\title{
The Impact of Accounting Information System on the Effectiveness of Public Enterprises: The Case of Kosovo
}

\author{
Shqipdona Hashani Siqani ${ }^{1}$, Nexhmie Berisha Vokshi ${ }^{2}$,
}

\begin{abstract}
:
Purpose: The aim of this paper is to measure the impact of the accounting information system on the effectiveness of public enterprises in Kosovo.

Design/methodology/approach: The study ensured primary data using survey methods by a considerable representative sample of public enterprises in Kosovo. The collected data, were analyzed by descriptive statistics, correlation and multiple linear regression analysis.

Findings: The analyzed results provide an overview of significant impact of accounting information system on effectiveness of public enterprises in Kosovo. The effectiveness of public enterprises has been expressed through quality of financial reporting, decisionmaking process, control system, performance and facilitation of transactions in general. Practical implications: The findings emphasize the importance of the accounting information system towards increasing effectiveness in public enterprises, respectively providing support for quality of financial reporting, decision-making process, control system, performance and facilitation of transactions process.

Originality/Value: The study results encourage and provide opportunities to increase the quality of the accounting information system, taking into consideration his importance on effectiveness at public enterprises.
\end{abstract}

Keywords: Accounting information system (AIS), effectiveness, the quality of financial reporting, decision-making process, control system, performance and facilitation of transactions process.

JEL codes: G34.

Paper type: Research article.

\footnotetext{
${ }^{1}$ University of Pristina, PhD candidate, Faculty of Economics, Department of Bank, Finance and Accounting, shaipdonahashani@hotmail.com

${ }^{2}$ Corresponding author, University of Pristina, Associate Professor, PhD, Faculty of Economic, Department of Bank, Finance and Accounting, nexhmie.berisha@uni-pr.edu
} 


\section{Introduction}

The accounting information system (on-going AIS) is a complex system, integrated to perform the potential accounting functions. The participators on AIS, have their own importance on increasing system quality and meeting system requirements in general. AIS in all enterprises provides meaningful information by merging enterprise actions and returning them into values or outcomes, from financial and non-financial issues, from internal and external sources, oriented in the pasts, present and futures actions/events. AIS functions are in gathering, processing, storage the data, to allocate sufficient and qualitative information for accounting information users. The relation between human resources, information technology, data, techniques, models and good accounting practices, support the enterprise to manage the knowledge effectively. The integrated components of AIS, designed in the proper way affect the information from AIS to be effective by requirements obverse with coordination and control purpose of enterprise. The enterprise is effective when the enterprise achieves its goals, mission or desired results. The effectiveness of AIS can be achieved through AIS elements contribution on expected results.

The aim of this paper is to measure the impact of the AIS on the effectiveness of public enterprises in Kosovo. Consequently, the effectiveness of AIS is when all AIS users have sufficient, adequate, reliable and convenient information to enhance the enterprise's effectiveness in quality of financial reporting, decision-making process, control system, performance and facility of transactions in general.

\section{Literature Review}

AIS is an information system that operates by gathering, processing and reporting financial activities in order to offer relevant information to support action during coordination, control and decision making process at enterprises (Libby and Waterhouse, 1996). Between organizational processes and AIS exist a strong relationship, therefore decision making process, structural organizational activities and other activities are not independent from financial information (Hopwood, 1978). AIS should be constructed and designed depending to the situations and conditions that are important for the organization (Kieso, Weygandt and Warfield, 2011). Effectiveness in organization is achieved when the organization has reached its goals (Daft, 1983) or its desired results (Oguntimehin, 2001). Effectiveness in organization measure how successful organization has been on reaching its mision, its consideration and sensitivity at environmental actions and its capacity to understand and to response market demands (Mccann, 2004).

AIS effectiveness, equivalently to organizational effectiveness, can be seen through a number of different perspectives. AIS effectiveness is achieved when all accounting information users have sufficient, accurate and relevant data for decision making process and control during business activities (Borthick and Clark, 1987). 
AIS is effective if it fits to enterprise during different conditions, by adapting technology and culture or values of the enterprise, interact with the surrounding environment, adopting the legislation, the nature and the organizational structure (Markus and Pfeffer, 1983). AIS is considered an important organizational mechanism, which is critical to effective decision-making and control in the organization (Hall, 2011).

The main reason why accounting information is generated is to facilitate decision and increase the quality of financial reporting to be complete and trustworthy (Ponemon and Nagoda, 1990). Relationship between AIS and sales growth, return on investment, number of clients and increase of cost-effectiveness in enterprise control is positive (Nwinee et al., 2016). Therefore, implementation of AIS and its success in the performance of the enterprise lie in direct connection (Grande, Estébanez and Colomina, 2011). The importance of AIS is expressed by enabling information growth within the organization, considering this as the main organizational feature for selecting different opportunities and problems and improving organizational performance in general (Hopwood, 1978).

Planning, decision making process, process implementation, control and coordination, information structuring and performance evaluation are functions that AIS should combine in the proper form to deliver effectiveness (Simons, 1987). AIS provides the quality of information in support of the organization's control, planning, decision making process and analysis of economic activities in accordance with the purpose and function of the AIS based on information technology (Susanto, 2015). Relationships between AIS and organizational effectiveness have a strong connection, which implies that access to AIS would lead to the organization's effectiveness (Hunton, 2002). The effectiveness of enterprise during AIS implementation is defined by improving the decision-making process, performance, internal controls and assistance in enterprise transactions (Bolon, 1998). Using AIS contributions, may result in better decision-making by administrators, more effective internal control, improved financial reporting quality, performance enhancement and facilitation of transaction process, consequently increasing effectiveness overall the enterprise (Sajady, Dastgir and Nejad, 2008; Huber, 1990).

\section{Research Methodology}

The data used in this study are primary data obtained from the results of questionnaire surveys on respondents. Questionnaires are built into three sections, which have been realized depending on the organizational structure of the enterprise. The first section carried out the general data about the participants and them AIS closeness at enterprises. The second and third section carried out the data about AIS elements and AIS contribution factors on the effectiveness of the enterprises. The questionnaires are address to complete the purpose of the paper throughout two main research questions: 
- Which AIS elements, have impact on AIS effectiveness?

- What is the impact of AIS on effectiveness of public enterprises?

Consequently, the hypotheses raised by research questions are:

- $\quad \mathrm{H}_{1}$ - AIS is affected by the AIS elements at public enterprises?

- $\mathrm{H}_{2}$ - AIS has impact on effectiveness of public enterprises?

Descriptions and comparisons of the data are done using descriptive analysis and other tests. The relationship between the variables were measured by correlation and for each hypothesis, a linear equation of multiplex regression was constructed. The size of the sample is adjusted to ensure of the accuracy of the results, with totally 150 questionnaires. Data processing is done using the Statistical Package for Social Science (SPSS, 20).

\section{Findings and Discussion}

The first section of questionnaire carried out the general data about the participants. The descriptive analysis represent that the questionnaire have been fulfill out of $59.3 \%$ men and $40.7 \%$ women. The education level of respondents shows that $75.3 \%$ participants had obtained a master's degree and $24.7 \%$ participants had obtained a bachelor degree. In terms of professional experience, $32 \%$ of participants answered that have over 5-10 year experience, $23.2 \%$ have over $10-15$ year experience, $15.3 \%$ have over 1-3 year experience, $14.8 \%$ have over 3-5 year experience and $14.7 \%$ have over 15 year experience. The analysis results represent that the position of participants over AIS contains out of 33\% user information, $21 \%$ designers of AIS, $17 \%$ producer of information and $29 \%$ other responsibilities. The professional qualification of respondents consisted of 33\% supervisor, $25 \%$ accountants, $18 \%$ administrators, $7 \%$ technical of accounting and $18 \%$ other qualification.

Figure 1. Position of participants over AIS and their professional qualification

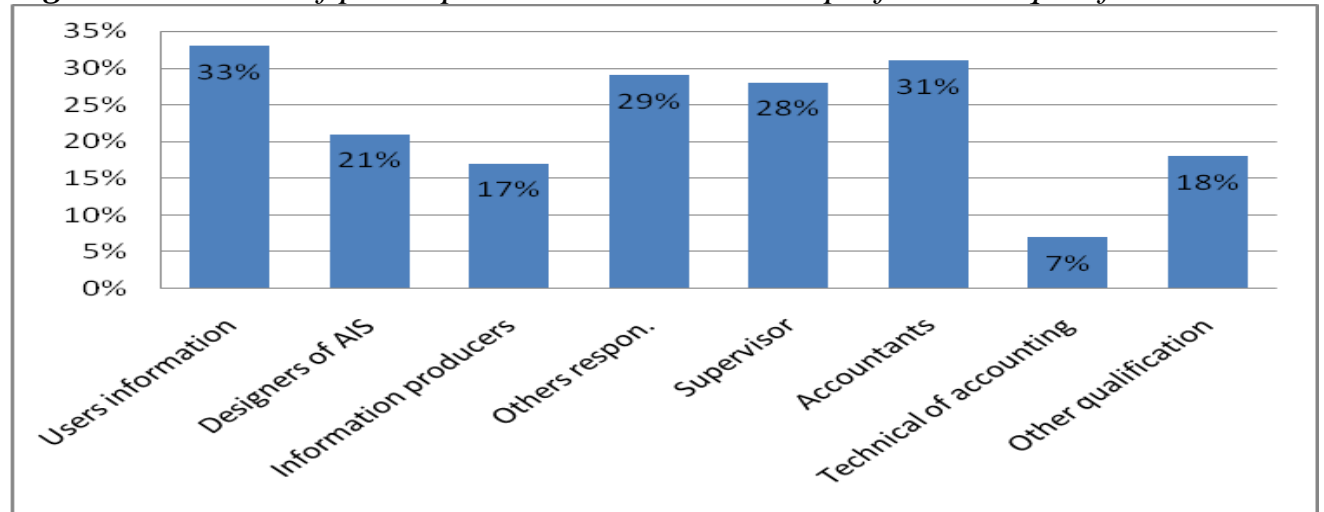

Source: Authors. 


\subsection{Analysis of data related to research questions and hypothesis H1}

AIS can be approached from its formal construction that implies the development of a system or technological processes and the development of relationships sides, respectively capacity building to achieve functional communication and coordination in the enterprise between organizational structures, tasks and committees for the purpose of influence on decision-making (Galbraith, 1973). The relationship between quality and information is determined by the quality of the system and the technical components (Wilkin and Tanya, 2003).

AIS designers are system components, system users, system developers, management and staff capability. Some of the accounting information characteristics are: focus, aggregation, orientation, time, financial/nonfinancial and qualitative /non-financial information. Other important elements in measuring the effectiveness of AIS are information technology, professional education, regulations, standards, laws and practices (Chenhall and Morris, 1986; Otley, 1980; Okour, 2016). Consequently, the constructed linear equationof multiplex regression to show about the impact of each AIS element on AIS effectiveness is:

$\mathrm{Y}=\alpha_{0}+\alpha_{1} \mathrm{X}_{1 \mathrm{i}}+\alpha_{2} \mathrm{X}_{2 \mathrm{i}}+\alpha_{3} \mathrm{X}_{3 \mathrm{i}}+\alpha_{4} \mathrm{X}_{4 \mathrm{i}}+\alpha_{5} \mathrm{X}_{5 \mathrm{i}}+\varepsilon$

Where: $\alpha_{0}, \alpha_{1}, \alpha_{2}, \alpha_{3}, \alpha_{4}, \alpha_{5}$-are coefficients of regression;

$\mathrm{X}_{1 \mathrm{i}}, \mathrm{X}_{2 \mathrm{i}}, \mathrm{X}_{3 \mathrm{i}}, \mathrm{X}_{4 \mathrm{i}}, \mathrm{X}_{\mathrm{i}^{-}}$elements of AIS (AIS designers, characteristics of AIS information, technology, professional education, regulations, standards, laws and practices);

Y- AIS effectiveness;

$\varepsilon-$ Error term.

Table 1 below shows the results from the linear equation of multiple regression analysis. It seems that AIS effectiveness is affected by AIS elements. Respectively, the AIS characteristics affected the AIS effectiveness with value 0.00 , AIS designers affected the AIS effectiveness with value 0.023 , technology affected the AIS effectiveness with value 0.041 , education level affected the AIS effectiveness with value 0.029 and laws, standard and regulation affected the AIS effectiveness with value 0.01 . All coefficient values reflected the statistically significant level of components, because they are under the critical p-value of 0.05 . Concretely the significant level is higher at the AIS characteristics continuing with laws, standard and regulation, AIS design, education level and laws and technology.

\subsection{Analysis of data related to research questions and hypothesis $\mathrm{H} 2$}

Effectiveness is a concept that can be measured by different models, but none of them can be adapted to different circumstances of organizations (Cameron, 1981). The organization effectiveness is measure through quality of financial reporting, decision-making process, control system, performance and facility of transactions 
process (Sajady, Dastgir and Nejad, 2008; Huber, 1990; Bolon, 1998; Hunton, 2002;

Simons, 1987).

Table 1. The impact of each AIS elements on AIS effectiveness

\begin{tabular}{|c|c|c|c|c|c|}
\hline \multirow[t]{2}{*}{ Model } & $\begin{array}{l}\text { Un } \\
\text { Coef }\end{array}$ & standardized & $\begin{array}{l}\text { Standardized } \\
\text { Coefficients }\end{array}$ & \multirow[t]{2}{*}{$\mathrm{t}$} & \multirow[t]{2}{*}{ Sig. } \\
\hline & B & Std. Error & Beta & & \\
\hline (Constant) & .716 & .320 & & 2.237 & .027 \\
\hline $\begin{array}{l}\text { Characteristics of } \\
\text { AIS }\end{array}$ & .316 & .058 & .395 & 5.474 & .000 \\
\hline AIS designers & .151 & .066 & .153 & 2.305 & .023 \\
\hline Technology & .122 & .059 & .131 & 2.062 & .041 \\
\hline Education Level & .122 & .055 & .167 & 2.203 & .029 \\
\hline $\begin{array}{l}\text { Laws, standards, } \\
\text { regulation }\end{array}$ & .136 & .052 & .165 & 2.601 & .010 \\
\hline
\end{tabular}

Source: Authors.

To analyze the variables' connection, the questions relate to the quality of financial report, decision making process, control systems, performance and transaction process we correlate AIS characteristics, AIS design, technology, education level, laws, standards and regulation questions throughout the factor analysis (Table 2).

Table 2. The correlation of variables

\begin{tabular}{|c|c|c|c|c|c|c|c|c|c|c|c|c|c|c|}
\hline $\begin{array}{l}\text { Com } \\
\text { p. }\end{array}$ & QFR & $\begin{array}{l}\text { AIS } \\
\text { elem. }\end{array}$ & Comp & DM & $\begin{array}{l}\text { AIS } \\
\text { elem. }\end{array}$ & Comp & $\mathrm{CS}$ & $\begin{array}{l}\text { AIS } \\
\text { elem. }\end{array}$ & Comp & $\mathrm{P}$ & $\begin{array}{l}\text { AIS } \\
\text { elem. }\end{array}$ & $\begin{array}{l}\text { Com } \\
\text { p. }\end{array}$ & FT & $\begin{array}{l}\text { AIS } \\
\text { ele } \\
\text { m. }\end{array}$ \\
\hline $\begin{array}{l}\text { QFR } \\
1\end{array}$ & 0.863 & -0.196 & DM1 & 0.903 & -0.149 & CS1 & 0.899 & & P1 & 0.93 & 0.179 & FT1 & 0.939 & \\
\hline $\begin{array}{l}\text { QFR } \\
2\end{array}$ & 0.8 & -0.48 & DM2 & 0.897 & -0.23 & CS2 & 0.843 & -0.241 & P2 & 0.928 & & FT2 & 0.887 & 0.348 \\
\hline $\begin{array}{l}\text { QFR } \\
3\end{array}$ & 0.787 & 0.273 & DM3 & 0.89 & -0.136 & $\mathrm{CS} 3$ & 0.835 & 0.332 & P3 & 0.854 & 0.159 & FT3 & 0.854 & 0.277 \\
\hline $\begin{array}{l}\text { QFR } \\
4 \\
\end{array}$ & 0.785 & 0.369 & DM4 & 0.845 & -0.429 & CS4 & 0.787 & -0.488 & P4 & 0.85 & -0.24 & FT4 & 0.847 & -0.195 \\
\hline $\begin{array}{l}\text { QFR } \\
5 \\
\end{array}$ & 0.765 & -0.371 & DM5 & 0.752 & 0.464 & CS5 & 0.787 & 0.552 & P5 & 0.831 & -0.115 & FT5 & 0.694 & -0.426 \\
\hline $\mathrm{AIS}_{1}$ & 0.746 & 0.367 & $\mathrm{AIS}_{1}$ & 0.744 & 0.529 & $\mathrm{AIS}_{1}$ & 0.75 & -0.283 & $\mathrm{AIS}_{1}$ & 0.804 & -0.517 & $\mathrm{AIS}_{1}$ & -0.212 & 0.788 \\
\hline $\mathrm{AIS}_{2}$ & 0.705 & -0.414 & $\mathrm{AIS}_{2}$ & 0.595 & -0.245 & $\mathrm{AIS}_{2}$ & 0.675 & -0.172 & $\mathrm{AIS}_{2}$ & 0.784 & -0.157 & $\mathrm{AIS}_{2}$ & & \\
\hline $\mathrm{AIS}_{3}$ & 0.621 & -0.558 & $\mathrm{AIS}_{3}$ & 0.361 & 0.63 & $\mathrm{AIS}_{3}$ & 0.674 & -0.533 & $\mathrm{AIS}_{3}$ & 0.696 & 0.533 & $\mathrm{AIS}_{3}$ & & \\
\hline $\mathrm{AIS}_{4}$ & 0.61 & 0.715 & $\mathrm{AIS}_{4}$ & & & $\mathrm{AIS}_{4}$ & 0.664 & 0.386 & $\mathrm{AIS}_{4}$ & 0.663 & -0.382 & $\mathrm{AIS}_{4}$ & & \\
\hline $\mathrm{AIS}_{5}$ & 0.504 & 0.519 & $\mathrm{AIS}_{5}$ & & & $\mathrm{AIS}_{5}$ & 0.405 & 0.556 & $\mathrm{AIS}_{5}$ & 0.443 & 0.857 & $\mathrm{AIS}_{5}$ & & \\
\hline
\end{tabular}

Source: Authors. 
The pattern matrix shows that between each variable and factors almost exists a linear relationship. The correlation coefficients ranging show the strong or weak correlation depending on the variables. To analyze the variable dependency, respectively the impact of AIS on effectiveness of public enterprises, we use the linear multiple regression equation (Table 3):

$Y=\alpha_{0}+\alpha_{1} X_{1 i}+\alpha_{2} X_{2 i}+\alpha_{3} X_{3 i}+\alpha_{4} X_{4 i}+\alpha_{5} X_{5 i}+\varepsilon$

Where $\alpha_{0}, \alpha_{1}, \alpha_{2}, \alpha_{3}, \alpha_{4}, \alpha_{5}$-are coefficients of regression;

$\mathrm{X}_{1 \mathrm{i}}, \mathrm{X}_{2 \mathrm{i}}, \mathrm{X}_{3 \mathrm{i}}, \mathrm{X}_{4 \mathrm{i}}, \mathrm{X}_{5 \mathrm{i}^{-}}$contribution of AIS (AIS designers, characteristics of AIS information, technology, professional education, regulations, standards, laws and practices);

$\mathrm{Y}-\mathrm{Y}_{1 \mathrm{i}}, \mathrm{Y}_{2 \mathrm{i}}, \mathrm{Y}_{3 \mathrm{i}}, \mathrm{Y}_{4 \mathrm{i}}$ - organization effectiveness (the quality of financial reporting, decision-making process, control system, performance and facilitation of transactions process);

$\varepsilon-$ Error term.

Table 3. The impact of each AIS elements on effectiveness of enterprises

\begin{tabular}{|c|c|c|c|c|c|}
\hline \multirow[t]{2}{*}{ Model } & \multicolumn{2}{|c|}{ Unstandardized Coefficients } & \multirow{2}{*}{ 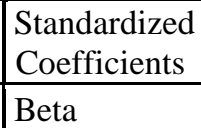 } & \multirow[t]{2}{*}{$\mathrm{t}$} & \multirow[t]{2}{*}{ Sig. } \\
\hline & B & Std. Error & & & \\
\hline (Constant) & 3.195 & .307 & & 10.411 & .000 \\
\hline $\begin{array}{l}\text { Characteristics of } \\
\text { AIS }\end{array}$ & .227 & .041 & .425 & 5.584 & .000 \\
\hline AIS designers & -.103 & .040 & -.197 & -2.610 & .010 \\
\hline Technology & .116 & .038 & .234 & 3.065 & .003 \\
\hline $\begin{array}{l}\text { Laws, standards, } \\
\text { regulation }\end{array}$ & .075 & .043 & .139 & 1.742 & .084 \\
\hline Education Level & .132 & .059 & .132 & 2.062 & .044 \\
\hline
\end{tabular}

Source: Authors.

Table 4 shows the results from the linear equation of multiple regression analysis. It seems AIS elements have impact on the effectiveness of enterprises. Respectively, the AIS characteristics affected the enterprises effectiveness with value 0.00 , AIS design affected the enterprises effectiveness with value 0.010 , technology affected the enterprises effectiveness with value 0.003 , education level affected the AIS effectiveness with value 0.044 and laws, standard and regulation affected the AIS effectiveness with value 0.084. All coefficients values reflected the statistically significant level of the components, because they are under the p-value critical coefficient which is 0.05 . Concretely, the significant level is higher at the AIS characteristics continuing with technology, AIS design, education level and laws, standard and regulation. 
To analyze the variable connection, we relate AIS characteristics, AIS design, technology, education level, laws, standards and regulation with the quality of financial report, decision making process, control systems, performance and transaction process throughout the factor analysis.

Table 4. The correlation of variables

\begin{tabular}{|l|l|l|l|l|l|}
\hline Component & $\begin{array}{l}\text { Quality of } \\
\text { financial } \\
\text { report }\end{array}$ & $\begin{array}{l}\text { Decision } \\
\text { making } \\
\text { process }\end{array}$ & Performance & $\begin{array}{l}\text { Control } \\
\text { process }\end{array}$ & $\begin{array}{l}\text { Transaction } \\
\text { process }\end{array}$ \\
\hline $\begin{array}{l}\text { Quality of } \\
\text { financial report } \\
\begin{array}{l}\text { Decision } \\
\text { making process }\end{array}\end{array}$ & 1.000 & .334 & .498 & .252 & -.020 \\
$\begin{array}{l}\text { Performance } \\
\text { Control process } \\
\text { Transaction } \\
\text { process }\end{array}$ & .434 & 1.000 & .180 & .131 & .154 \\
& -.020 & .180 & 1.000 & .153 & -.082 \\
& .131 & .153 & 1.000 & .014 \\
Source: & .154 & -.082 & .014 & 1.000 \\
\hline
\end{tabular}

Source: Authors.

The pattern matrix shows that correlation coefficients' significant level is stronger at the decision making process continuing with quality of financial report, performance, control process, and transaction process.

\section{Conclusion}

This article presented the impact of the accounting information system on the effectiveness of public enterprises in Kosovo, according the interdependent and complex nature of the accounting information system. The collection of data for the public enterprises and connection between variables was conducted through a questionnaire and were processed using quantitative analytical method. The result verified by descriptive as well as by analysis of significance and correlation between questions and variables.

The results determined the relationship between AIS elements and AIS effectivenss. Respectively, characteristics of AIS information, AIS designers, technology, professional education, laws, regulations, standards and practices affected the AIS effectivenss on public enterprises.

Consequently, either AIS element has impact on effectiveness of public enterprises. Based on the research result, we can determined that effectiveness of enterprises or the quality of financial report, decision making process, control systems, performance and transaction process significantly are influenced by AIS elements. Respectively, the interconnection or dependency of effectiveness of enterprises is affected from AIS elements. 
The information distributed by effective AIS aims to improve and facilitate the decision-making process, enhances communication and coordination through enterprise, influence the quality of financial reports, improve control process mechanisms and increase performance of enterprises.

\section{References:}

Bodnar, H. and Hopwood, W. 2004. Accounting Information Systems (9nd ed.). Upper Saddle River, New Jersey: P.E. Inc, Ed.

Bolon, M. 1998. Factors influencing the alignment of accounting information systems in small and medium sized Malaysian manufacturing firms. JOURNAL??

Borthick, F. and Clark, R.L. 1987. Making accounting information systems work: An empiracal investigation of the creative thinging paradigm. Journal of Information Systems, 4, 48-62.

Cameron, K. 1981. New Directions for Program Evaluation: Measuring Effectiveness. San Francisco: Jossey-Bass , 11.

Chang, Y. 2001. Contingency factors and accounting information system design in Jordanian companies. Journal of Accounting Information System, 8, 1-16.

Chenhall, R. and Morris, D. 1986. The impact of structure, environment and interdependence on the perceived usefulness of management accounting systems. The Accounting Review, 61, 16-35.

Clarke, J. 2001. Accounting for Manager (2nd ed.). C.I. Oak Tree Press.

Curtis, G. 1995. Business Information Systems: Analysis, Design and Practice. Wokingham: Addison-Wesley, Ed.

Daft, R. 1983. Organization theory and design. Minnesota: W.P. Company, Ed.

Daneila. M., Vassen, J. and Dameri. P. 2013. Accounting Information System for Decision Making. S.V. Berlin, Ed.

Doll, W.J. and Torkzadeh, G. 1998. The measurement of end-user computing (12 ed.). MISQ.

Galbraith, R. 1973. Designing Complex Organizations. Addison-Wesley, Ed.

Grande, U., Estébanez, P. and Colomina, M. 2011. The impact of Accounting Information Systems (AIS) on performance measures: Empirical research. The International Journal of Digital Accounting Research, 11, 25-46.

Hall, J. 2011. Accounting Information Systems (7nd ed.). Mason: S.W.C. Learning, Ed.

Hopwood, A.G. 1978. Towards an Organizational Perspective for the Study of Accounting and Information. Accounting, Organization and Society, Vol X???, 3-13.

Huber, G. 1990. A theory of the effects of advanced information technologies on organizational design, intelligence, and decision making. Academy of Management Review, 1(15), 47-71.

Hunton, J. 2002. Blending information and communication technology with accounting research. Accounting Horizons, 16, 55-67.

Kieso, E., Weygandt, J. and Warfield, D. 2011. Intermediate Accounting (14 ed.). John Wiley \& Sons, Ed.

Libby, T. and Waterhouse, T.J. 1996. Predicting Change in Management Accounting Systems. Journal of Management Accounting Research, 8, 137-150.

Markus, L. and Pfeffer, J. 1983. Power and the design and implementation of accounting and control systems. Accounting, Organizations and Society, 8(2), 205-218.

McCann, J. 2004. Organizational Effectiveness: Changing Concepts for Changing Environments. Human Resource, 27, 42-50. 
Nicolaou, A. 2001. Integrated Information systems and interorganizational performance: the role of management accounting systems design. Advances in Accounting Behavioral Research, 14, 117-141.

Nwinee, K., Akpos, Y., Vincent, N. and Ibinabo, T. 2016. Impact of Accounting Information System on Organizational Effectiveness: A Study of Selected Small and Medium Scale Enterprises in Woji. Journal of Research International, 3, 974-982.

O'Brien, A. and Maracas, M. 2010. Introduction to Information Systems (15nd ed.). NY: M.H. Irwin, Ed.

Oguntimehin, A. 2001. Teacher effectiveness: Some practical strategies for successful implementation of universal basic education in Nigeria. African Journal of Educational Management, 9, 151-161.

Okour, S. 2016. The Impact of the Effectiveness of Accounting Information Systems on Operational Issues. Journal of Social Sciences, 5, 264-276.

Otley, T. 1980. Accounting, Organizations and Society. The Contingency Theory of Management Accounting: Achievements and Prognosis, Vol X???, 412-428.

Ponemon, A. and Nagoda, J. 1990. Perceptual Variation and the Implementation of accounting Information Systems: An Empirical Investigation. Journal of Information Systems, 4, 1-14.

Romney, B. and Steinbart, J. 2012. Accounting Information System (12nd ed.). E.P.E. Limited, Ed., England, Global Edition.

Sajady, H., Dastgir, M. and Nejad, H. 2008. Evaluation of the Effectiveness of Accounting Information Systems. International Journal of Information \& Science Technology, 6.pp???

Simons, R. 1987. Accounting Control Systems and Business Strategy: An empirical analysis. Accounting, Organization and Society, Vol X???, 357-374.

Susanto, A. 2015. What Factors Influence the Quality of Accounting Information (13 ed.). I.J.A.B.E.R.???

Sutton, S. 1992. Can we Research a Field we Cannot Define? Toward an Understanding of the AIS discipline. Advances in Accounting Information Systems, Vol X??? 1-13.

Teru, P., Idoku, I. and Ndeyati, J. 2017. A Review of the Impact of Accounting Information System for Effective Internal Control on Firm Performance. Indian Journal of Finance and Banking, 1, 51-59.

Wilkin, C. and Tanya, L. 2003. Development of an Interment to Evaluate the Quality of Deliver Information System. Proceedings of the 36th Hawaii International Conference on System Sciences. Deakin University.

$\mathrm{Xu}, \mathrm{H} .2009$. Data quality issues for AIS' implementation: systems, stakeholders, and organizationaL. Journal of Technology Research, Vol X??, ppXXX??.

Yang, H., Lin, S. and Koo, L. 2011. The impact of computerized internal controls adaptation on operating performance. African Journal of Business Management Vol X??, ppXXX??.

Zimmerman, J. 1995. Accounting for Decision-making and Control. C. Irwin, Ed. 